\title{
GESTÃO DA SUSTENTABILIDADE AMBIENTAL: A PERSPECTIVA DAS COMPETÊNCIAS
}

ENVIRONMENTAL SUSTAINABILITY MANAGEMENT: THE COMPETENCE PERSPECTIVE

Luciano Munck

Professor Associado do Centro de Estudos Sociais Aplicados - Universidade Estadual de Londrina (UEL). Londrina, PR, Brasil

E-mail: munck@uel.br

Bárbara Galleli *

Doutoranda em Administração na Universidade de São Paulo.

São Paulo, SP, Brasil

E-mail: b.gallelidias@gmail.com

Hamilton Luiz Corrêa

Professor da Universidade de São Paulo.

São Paulo, SP, Brasil

E-mail: hamillco@usp.br

\section{RESUMO}

Este artigo objetiva delinear um framework capaz de representar e orientar o acontecimento da sustentabilidade ambiental nas organizações. Orientando-se pela pesquisa teórica e proposições do modelo de Munck, Munck e Borim-de-Souza (2011) o FRASOR, foi desenvolvido um ciclo de aprendizagem que permeia a abordagem das competências e a teoria do Agir Organizacional. Espera-se que o referido framework sirva de referência para a operacionalização e gestão da sustentabilidade ambiental em contexto organizacional, algo não explicado pelo FRASOR. Serão demonstradas, em uma relação sistêmica e processual, a mobilização dos recursos, a adequação estratégica e a sequência para se chegar à sustentabilidade ambiental nas organizações.

Palavras-chave: Sustentabilidade organizacional. Sustentabilidade ambiental. Competência organizacional. Framework. Ciclo de aprendizagem.

Data de submissão: 30 de setembro de 2015.

\section{ABSTRACT}

This paper aims to outline a framework able to represent and guide the occurrence of environmental sustainability in organizations. Guided by theoretical research and by the propositions of the model of Munck, Munck and Borim-de-Souza (2011) - the FRASOR, it was outlined a cycle of learning that permeates the competence approach and the theory of Organizational Acting. It is expected that the referred framework will serve as a reference for the operation and management of environmental sustainability in an organizational context. Something not explained by FRASOR. In a systemic and procedural relationship, it will be demonstrated resource mobilization, strategic fit and the sequence to get to environmental sustainability in organizations

Keywords: Organizational sustainability. Environmental sustainability. Organizational competence. Framework. Cycle of learning.

Data de aprovação: 22 de junho de 2016. 


\section{INTRODUÇÃO}

Ainda que passíveis de desconfianças e apontamentos críticos, em geral, é notável o movimento de organizações governamentais e não governamentais, da sociedade civil, dos próprios indivíduos, de empresas e instituições de ensino em busca pela compreensão de como tornar o desenvolvimento sustentável possível. Em meio ao que pode ser chamado de 'revolução sustentável' (STARIK; KANASHIRO, 2013), observa-se que há, de maneira cada vez mais explícita, alterações no comportamento de organizações, instituições e indivíduos, o qual passa a ser influenciado em favor da sustentabilidade. As organizações privadas recebem destaque neste contexto na medida em que, perceptivelmente, além do potencial em causar impactos positivos e negativos, possuem também grande capacidade de influenciar e até mesmo determinar o desenvolvimento das comunidades onde se encontram inseridas.

A pesquisa realizada pela UN Global Compact em parceria com a multinacional Accenture, denominada "CEO Study on Sustainability 2013", com mais de mil executivos de vinte e sete setores da economia, em cento e três países, revelou que para 93\% destes líderes, a sustentabilidade representa a chave para o sucesso empresarial. Além de um campo de oportunidades, a sustentabilidade tornou-se uma rota para a vantagem competitiva. Em contraste, a pesquisa indicou que a maioria dos CEOs consultados $67 \%$ - não acredita que as empresas estão fazendo o suficiente para enfrentar os desafios globais de sustentabilidade. Segundo relatos dos CEOs, as empresas estão contidas devido à falta de ousadia, de entendimento e de uma abordagem de gestão mais holística. Em um cenário de desafios cada vez mais intensos em que o papel das organizações privadas se mostra determinante para o desenvolvimento sustentável global, circunstâncias como esta são, no mínimo, alarmantes.

Segundo Stubbs e Cocklin (2008), embora haja um corpo substancial na literatura acerca de diferentes modelos, a compreensão da sustentabilidade, para o meio empresarial, assim como a ocorrência de sua operacionalização, ainda não se apresentam de forma consistente. Nota-se um maior número de iniciativas orientadas para a divulgação das ações organizacionais ditas sustentáveis, muitas denotam uma distância entre a retórica e a realidade quando o assunto é a implantação de práticas de gestão (HANH; SCHEEMESSER, 2005; BARKEMEYER et al., 2014).

Outro desafio para implementação de práticas está na dissociação da gestão ambiental das demais atividades organizacionais. A despeito do reconhecimento da abrangência de elementos que envolvem a sustentabilidade, vários países, instituições e organizações incorporam uma definição estreita acerca do assunto, limitando-se a tratar apenas do pilar ou da sustentabilidade ambiental (Hacking e Guthrie, 2008). Na esfera empresarial, isso provavelmente se deve à sua associação mais objetiva e direta com as questões ambientais, também mais visíveis e alardeantes aos olhos da sociedade, além de ser simpática em relação aos meios para sua quantificação (DYLLICK; HOCKERTS, 2002; YOUNG; TILLEY, 2006). Contudo, isso é pouco em relação a como articular esses conceitos sistemicamente para que se tornem ações e decisões organizacionais voltados à sustentabilidade.

Munck, Munck e Borim-de-Souza (2011), com bases em incômodos e pressupostos semelhantes aos aqui relatados, elaboraram um Framework Representativo do Acontecimento da Sustentabilidade Organizacional (FRASOR). Os autores, na perspectiva da ausência de um único paradigma que concedesse sustentação ao estudo, fundamentaram-se na abordagem teórica do Agir Organizacional (MAGGI, 2006), 
unida à lógica das competências (MILLS et al. 2002) e de ambas à abordagem integrativa do TBL (ELKINGTON, 1999).

Considerando as discussões até aqui realizadas, a fim de contribuir com uma nova perspectiva para avançar no conhecimento, o presente artigo oferecerá um aprimoramento ao modelo de Munck, Munck e Borim-de-Souza (2011). A partir do detalhamento conceitual e prático aqui desenvolvido e mantendo coerência com as bases do FRASOR, almeja-se delinear um framework capaz de representar e orientar o acontecimento da sustentabilidade ambiental nas organizações. Espera-se que ele atue como referência para a sua operacionalização e gestão.

A pesquisa caracteriza-se como teórica e qualitativa, pois se desenvolve com o fim de instigar a reflexão e interpretação da realidade envolta às teorizações da S.A. (FLICK, 2009). De acordo com Jabareen (2009), quando uma pesquisa busca conciliar conceitos, informações, variáveis e discussões para a formação de uma nova abordagem explicativa - ou avançar na existente, como a proposição contida neste artigo - a respeito de um fenômeno multidisciplinar, como a S.A., persiste uma tentativa de se fundamentar um estudo teórico que dê conta de explorar os relacionamentos em investigação. No Quadro 1 elenca-se os temas centrais abordados, o foco de investigação e os principais autores referenciados.

Quadro 1 - Estrutura de investigação temática e procedimentos de pesquisa.

\begin{tabular}{|c|c|c|}
\hline Temas pesquisados & O que investigar? & Principais Autores \\
\hline $\begin{array}{l}\text { Competências } \\
\text { Organizacionais }\end{array}$ & $\begin{array}{l}\text { Abordar os principais conceitos a apresentar a } \\
\text { foma pela qual uma competéncia } A \\
\text { construida, a fim de criar uma base para } \\
\text { sugerir a sustentabilidade ambiental como } \\
\text { uma competência. }\end{array}$ & $\begin{array}{c}\text { Mills et al., 2002; } \\
\text { Fleury o Fleury, 2004; } \\
\text { Spanos a Prastacos, 2004; } \\
\text { Fernandes; Fleury e Kills, } 2006\end{array}$ \\
\hline $\begin{array}{l}\text { Sustentabilidade } \\
\text { Organizacional: } \\
\text { modelos conceituais } \\
\text { e prdicos }\end{array}$ & $\begin{array}{l}\text { Apresentar a sintetizar conceitcs que } \\
\text { caracterizem a sustentabilidade em contexto } \\
\text { organizacional. }\end{array}$ & $\begin{array}{c}\text { Elkington, 1999; } \\
\text { Dylick e Hockerts, 2002; } \\
\text { Van Marrewijk e Werre, 2003 } \\
\text { Valente, 2012. }\end{array}$ \\
\hline $\begin{array}{l}\text { Sustentabilidade } \\
\text { Ambiantal: }\end{array}$ & $\begin{array}{l}\text { Apresentar e sintetizar conceitos e premissas } \\
\text { da SA que permitam explicar e detalhar sua } \\
\text { gestlo no contexto da sustertabilidade } \\
\text { organizacional. }\end{array}$ & $\begin{array}{l}\text { Kranje e Glavic, 2005; } \\
\text { Asadi ef el, 2006; } \\
\text { Moreli, 2011. }\end{array}$ \\
\hline Ecoeficiência & $\begin{array}{l}\text { Apresentar e sintetizar conceilcs que } \\
\text { permicam explcar a Ecceficiencia como uma } \\
\text { das compeléncias queviablizam a S.A. }\end{array}$ & $\begin{array}{l}\text { Pielto, } 2003 \\
\text { Braungart. Mcdonough e Bollinger, } \\
\text { 2006, } \\
\text { Schatfel.2010: }\end{array}$ \\
\hline $\begin{array}{c}\text { Justiça } \\
\text { Socioambiental }\end{array}$ & $\begin{array}{l}\text { Apresectar e sintetizar concellce que } \\
\text { permitam explicar a Justica Socisambiental } \\
\text { como uma das competencias que vabilizam a } \\
\text { SA. }\end{array}$ & $\begin{array}{c}\text { Rego, Carvalhe, Leze, Freire e Veira. } \\
\text { 2000; } \\
\text { Ascerald, 2002; } \\
\text { Whitemon, 2009 }\end{array}$ \\
\hline
\end{tabular}

Fonte: Elaborado pelos autores.

\section{TEORIA DAS COMPETÊNCIAS ORGANIZACIONAIS}

As raízes teóricas do conceito de competência organizacional estão imbricadas na abordagem da visão baseada em recursos (RBV, do inglês resource based view) (FERNANDES; FLEURY; MILLS, 2006). Nessa perspectiva, uma organização pode ser entendida como um conjunto de recursos empregados para gerar riquezas. Os recursos são elementos potenciais, um estoque à disposição da organização, cuja simples existência não se traduz necessariamente em desempenho. Na maioria das circunstâncias, não são os recursos, mas os processos geradores de entrega destes recursos que geram mais diretamente a vantagem competitiva (LEWIS, 2003). É fundamental que os recursos sejam mobilizados, coordenados, articulados e entregues para se transformarem em competências. $O$ entendimento desse processo é capaz de garantir 0 
desempenho organizacional desejado, pois a partir do estudo das inter-relações entre recursos será possível entender uma competência, sendo possível, assim, aprimorá-la a partir dos recursos identificados (MILLS et al., 2002).

A competência organizacional pode ser entendida como um conjunto de recursos coordenados que geram valor à organização, são difíceis de imitar, podem ser transferidos a outras áreas, produtos ou serviços da organização, e impactam o desempenho organizacional em um fator-chave a seu sucesso (MILLS et al. 2002; FERNANDES, FLEURY; MILLS, 2006). Enquanto os recursos são considerados finitos em oferta e depreciáveis quando compartilhados com terceiros, as competências referem-se aos processos dinâmicos, não findos, específicos e contextualizados da organização que são difíceis de imitar e acumulam aprendizagem, no longo prazo (SPANOS; PRASTACOS, 2004).

São cinco categorias de competências organizacionais definidas por Mills et al. (2002): competência foco (core competence); competência chave; competência da unidade de negócio; competência de suporte e capacidade dinâmica. Estas cinco categorias são todas dependentes da existência de recursos diversos, tangíveis ou intangíveis, que deverão ser articulados de forma intencional. A abordagem da RBV, como então estruturada, sugere que as competências são parte da estrutura organizacional e, como tal, devem influenciar o delineamento da estratégia, em resposta às demandas ambientais (WERNERFELT, 1984; BAKER et al., 1997).

Fleury e Fleury $(2004 ; 2008)$ argumentam que a competitividade de uma organização é determinada pela inter-relação dinâmica e cíclica entre as suas competências e a estratégia. A abordagem dos recursos faz o processo de formulação da estratégia e a formação de competências constituírem um círculo que se retroalimenta. A implantação da estratégia gera novas configurações de recursos e novas competências que, por sua vez, irão influenciar novamente a formulação da estratégia. A escolha estratégica é então realizada a partir do mapeamento dos recursos e das competências organizacionais e da análise do ambiente.

A sustentabilidade se apresenta como uma demanda social e a incorporação de suas premissas pelas organizações não só se mostra necessária, como também demandante de novos princípios de gestão que não estejam ancorados na competição a todo custo e na busca desenfreada por vantagem competitiva. Almeja-se aqui, com a estruturação das bases de gestão para a Sustentabilidade Organizacional, a sustentação de um novo agir organizacional diferenciado. Pois entende que a vantagem competitiva é considerada como um efeito natural de sua incorporação e não com um objetivo central.

Ao refletir sobre as definições concedidas pelos autores referenciados até então, chegou-se a uma definição para competência organizacional mais alinhada aos preceitos da sustentabilidade: "Um agir coletivo e processual, fundamentado na mobilização de recursos, em permanente construção, reconhecido como de alta qualidade e que agrega valor à organização, aos indivíduos e à sociedade".

Ao longo dos anos, abordagens de gestão baseadas em competências provaram ser alicerces fundamentais em muitas funções organizacionais, principalmente às relacionadas à gestão de pessoas, além de possibilitar o alcance de benefícios substanciais ao fomentar o alinhamento entre políticas de gestão de pessoas e a estratégia da empresa (VAKOLA; SODERQUIST; PRASTACOS, 2007). Assim, é possível inferir que a formação de competências em uma organização envolve: a competência dos indivíduos com os quais ela se relaciona; a dinamicidade de sua estrutura e recursos; seus valores e cultura; bem como o contexto externo. Ao se definir e se avaliar as entregas esperadas para as competências organizacionais criam-se 
parâmetros para se dizer quão bem, ou não, a organização tem o desempenho adequado para as suas atividades centrais. Como a competência permeia toda a gestão da organização, pode assumir a condição de orientar sua atuação estratégica, tática e operacional.

O modelo de gestão articulado por competências e suas características é assumido a partir das contribuições de Drejer (2002), Zarifian (2003), Fleury e Fleury (2004), Markus, Cooper-Thomas e Allpress (2005), Maggi (2006), Vakola, Soderquist e Prastacos (2007), e definido como uma maneira pela qual uma organização se estabelece para gerenciar e orientar o alinhamento entre estratégias organizacionais, objetivos, pretensões individuais e condições ambientais, a partir de uma abordagem prospectiva e proativa. Um modelo de gestão articulado por competências deve ser tão específico quanto seu conteúdo, de forma que tenha suas definições, características, conceitos e indicadores de mensuração apropriadamente definidos.

Nesse contexto, lança-se a ideia de que a gestão articulada por competências, frente às suas estrutura e pilares, pode ser compreendida como uma resposta plausível aos anseios sociais por ações organizacionais voltadas para a sustentabilidade. A gestão por competências, ao exigir o interligar e o aproximar de indivíduos e organização, propicia uma ambiência facilitadora de discussões sobre a problemática relação entre os interesses econômicos, ambientais e sociais.

\section{O FRASOR, A SUSTENTABILIDADE ORGANIZACIONAL E OS DETALHAMENTOS DA SUSTENTABILIDADE AMBIENTAL}

Segundo Munck, Munck e Borim-de-Souza (2011), autores responsáveis pelo desenvolvimento do FRASOR, a Sustentabilidade Organizacional (S.O.) constitui-se em uma competência central sob a responsabilidade do nível estratégico. Quando convertida em uma competência, adquire bases conceituais e práticas para sua gestão à medida que ganha objetividade na definição dos parâmetros para sua avaliação. Esta objetividade permite promover e relatar a eficiência em sua gestão, ou seja, indicar se há a melhor articulação dos recursos. A S.O., de acordo com o FRASOR, é uma competência central, composta e viabilizada pelas competências chave: Sustentabilidade Econômica (S.E.), Sustentabilidade Ambiental (S.A.) e Sustentabilidade Social (S.S.), que por suas vezes, são viabilizadas e compostas pela interação e atendimento de outras três competências de suporte combinadas duas a duas, Ecoeficiência, Justiça Socioambiental e Inserção Socioeconômica. No caso da Sustentabilidade Ambiental, combina-se, em específico, Ecoeficiência e Justiça Socioambiental. As seis competências compreendem os agires organizacionais capazes de orientar a gestão da sustentabilidade. As competências de suporte representam de fato os meios de operacionalização para o alcance das competências chave, situadas sob responsabilidade do nível tático. Estas, por seu turno, orientam e relatam o acontecimento da competência central (S.O.), sob responsabilidade do nível estratégico, a qual por seu caráter sistêmico e retro alimentador, exige, orienta, retrata e promove todo este processo sistêmico, conforme observado na Figura 1. 
Figura 1 - Framework representativa do acontecimento da Sustentabilidade Organizacional

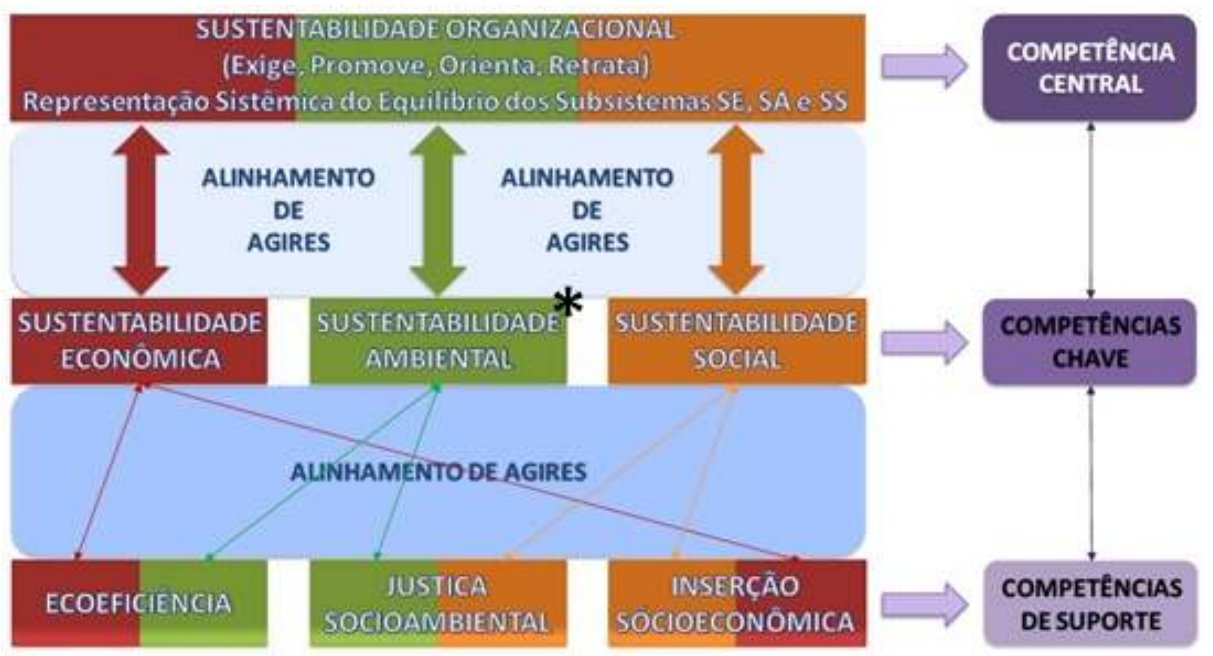

Fonte: Munck, Munck e Borim-de-Souza (2011, p. 155)

Ao estudar-se o framework em questão verificou-se que ele apresenta avanços com respeito ao tratamento da sustentabilidade frente a seus respectivos componentes, quando comparado a outros modelos da mesma natureza (Azapagic, 2003; Wheeler et al., 2005; CHENG; FET; HOLMEN, 2010; MOLTENI; PEDRINI, 2010). Além disso, trabalhos anteriores que utilizaram a mesma base teórica que o FRASOR (BORIM-DE-SOUZA, 2010; MUNCK et al., 2013) ou o tiveram como objeto de estudo (MUNCK; GALLELI, 2012; MUNCK, 2013; GALLELI et al., 2014), o apontam como um framework consistente e pertinente ao atendimento das necessidades de gestão da sustentabilidade nas organizações.

Apresentadas as bases do FRASOR, cabe agora direcionar-se para o enfoque deste artigo, a Sustentabilidade Ambiental (S.A.). Apesar de citações na década de 1970, foi na década de 1990 que as proposições da S.A. tomaram força, sendo o trabalho de Goodlan (1995) o mais reconhecido em âmbito acadêmico. Goodlan associa a noção dos limites e finitude dos serviços do ecossistema à capacidade de absorção da Terra, procurando melhorar o bem-estar humano por meio da proteção das fontes de matérias primas utilizadas para suprir as necessidades da sociedade (MOLDAN, JANOUSKOVA; HAK, 2012).

Asadi et. al (2008) discorrem sobre a definição de S.A. de forma integrada às sustentabilidades social e econômica. Para os autores, a S.S. diz respeito às condições sociais necessárias para amparar a S.A., pois se entende que os recursos naturais são utilizados dentro de um contexto social e são suas regras e valores que determinam a sua distribuição nas gerações atual e futuras. Do mesmo modo, as sustentabilidades econômica e social estão interligadas, haja vista a primeira implicar facilidade na redução da pobreza, auxiliando a busca pela S.S. e, por outro lado, a segunda, por meio do desenvolvimento social, é capaz de promover a S.E.. Porém, que para alcançar ambas, S.S. e S.E., é preciso mobilizar os recursos ambientais (ASADI et. al, 2008; MORELLI, 2011).

Tratando-se da esfera organizacional, para Munck, Munck e Borim-de-Souza (2011), a S.A. refere-se à viabilidade ambiental das atividades organizacionais. A S.A. corresponde a um subsistema da S.O., representante da eficácia da justiça socioambiental e da ecoeficiência. Abrange a prevenção dos impactos gerados pela organização nos sistemas naturais e vai além de registrar a conformidade com as regulamentações governamentais e de iniciativas como reciclagem ou utilização eficiente de recursos 
energéticos. É ainda pautada pela avaliação dos impactos gerados pelos produtos, pelos processos e serviços realizados na organização, pela eliminação de gastos desnecessários e de emissões elevadas, além da minimização de práticas que podem afetar o acesso das gerações vindouras aos recursos naturais críticos.

A adoção da ideia da gestão da S.A. é justificada por muitos em virtude do entendimento das empresas de que os consumidores e investidores valorizam o tratamento dispensado ao meio ambiente, que as decisões estratégicas integradas à gestão ambiental conseguem vantagens competitivas com redução de desperdícios, custos e incremento nos lucros. Os sistemas de gestão ambiental que envolvem técnicas como a Análise do Ciclo de Vida, a Produção Mais Limpa, a Produção Limpa, a Avaliação do Ciclo de Vida do Produto e o Ecodesign aparecem como as formas de operacionalização e regulação do meio ambiente utilizadas significativamente pelas organizações (POLIZELLI; PETRONI; KRUGLIANSKAS, 2005). Entretanto, adotar um sistema ou ferramentas de gestão ambiental não significa ser ambientalmente sustentável. Com base em Dyllick e Hockerts (2002) e Munck, Munck e Borim-de-Souza (2011), é possível constatar que a gestão ambiental fica aquém dos pressupostos da S.A., bem por isso, seria equivocado pareá-las.

Conforme já ressaltado, a S.A. viabiliza-se a partir de suas duas competências de suporte, a Ecoeficiência e a Justiça Socioambiental, as quais serão explicadas a seguir.

\section{Ecoeficiência}

O conceito "ecoeficiência" já possui razoável número de estudos nacionais e internacionais. Interpretada de várias maneiras, chega a ser equivocadamente traduzida como sinônimo da sustentabilidade pelas empresas. Embora inegavelmente constitua parte do quadro estratégico de uma organização, como conceito único ou basicamente operacional, a ecoeficiência é insuficiente e apenas uma parte da sustentabilidade organizacional (DYLLICK; HOCKERTS, 2002; YOUNG; TILLEY, 2006).

No ano 2000, o conceito foi consolidado, a partir de uma publicação do World Business Council for Sustainable Development - WBCSD (2000), que definiu ecoeficiência como o fornecimento de bens e/ou serviços a preços competitivos, que satisfaçam a necessidade dos consumidores e ao mesmo tempo, proporcionem qualidade de vida e reduzam o impacto ambiental, bem como o consumo de recursos. Se não é a definição mais aceita entre os acadêmicos e empresários, esta representa um marco para a ecoeficiência, sua legitimação no meio organizacional. A partir daí inúmeras outras definições surgiram (BRAUNGART; MCDONOUGH; BOLLINGER, 2006).

Braungart, McDonough e Bollinger (2006) concebem a ecoeficiência como uma estratégia de ação social cuja finalidade é reduzir o uso de materiais na economia, minimizar impactos ambientais indesejáveis e produzir níveis relativamente mais altos de riquezas econômicas, que deverão ser distribuídas de maneira mais justa. Nesse mesmo contexto, Piotto (2003) discorre sobre a ecoeficiência como o saber combinar desempenho econômico e ambiental tendo em vista o contexto externo, ao mesmo tempo em que reduz impactos ambientais; utiliza mais racionalmente matérias-primas e energia; reduz os riscos de acidentes e melhora a relação da organização com stakeholders. Guenster et al. (2011) também apresentam uma concepção semelhante, em que a ecoeficiência reflete a governança ambiental da empresa para além do que é indicado pelo cumprimento da legislação ambiental e políticas de controle de poluição. 
Por outro lado, várias são as críticas encontradas a respeito de versões mais estreitas do conceito, principalmente no sentido de que a ecoeficiência se tornou o modus operandi para muitas organizações interessadas em criar mais valor com menos impacto (MILNE; KEARINS; WALTON, 2006). Esta ideia de ecoeficiência é reduzida à eficiência econômica em detrimento da eficiência ecológica, ou seja, desequilibrada frente às exigências ambientais (SCHAFFEL, 2010). Além disso, limita o conceito a uma gestão do fluxo de matéria prima e energia, desconectado do contexto socioeconômico e cultural local (HUKKINEN, 2001).

Apesar do critério mais amplamente aceito para alcançar a S.O. constituir-se na eficiência empregada na gestão do meio ambiente aliada ao desempenho econômico da empresa, este discurso estreito da ecoeficiência não é compatível com a perspectiva dinâmica da sustentabilidade (SCHAFFEL, 2010). No curto prazo, as estratégias ecoeficientes possuem, de certo modo, potencial para reduções tangíveis nos impactos ambientais causados pelas atividades empresariais, assim como apresentam oportunidades para a redução de custos. Porém, no longo prazo, tais estratégias são insuficientes para atingir os objetivos econômicos e ambientais que prezam os conceitos mais robustos da ecoeficiência (BRAUNGART; MCDONOUGH; BOLLINGER, 2006). Depreende-se que as definições estreitas de ecoeficiência tampouco são sinônimas da S.A. nas organizações.

O problema, contudo, não está no conceito de ecoeficiência, mas sim em sua incorporação e aplicação dentro de uma proposta de gestão mais abrangente. É nesse sentido que se assume como base deste trabalho a vertente que envolve os conceitos robustos da ecoeficiência (PIOTTO, 2003; BRAUNGART; MCDONOUGH; SCHAFFEL, 2010; GUENSTER et al., 2011), uma vez que abarcam não somente aspectos referentes ao desempenho financeiro e ambiental, mas também questões que abordam os relacionamentos da organização com o meio.

\section{Justiça Socioambiental}

Antes de avançar nas discussões sobre justiça ambiental, social e organizacional, as quais fundamentarão o conceito de justiça socioambiental nas organizações, faz-se necessário esclarecer o conceito de justiça aqui adotado. A partir das contribuições de Rawls (1997) e Fortin e Fellenz (2008), admitese a justiça como um atributo básico da ordem social, pela qual, distribuem-se os direitos e deveres e se determinam a distribuição das vantagens obtidas com a cooperação social, para os quais não existe padrão universal.

No âmbito das organizações, as pesquisas sobre justiça já ocupam um espaço notório. A justiça, estando indelevelmente inscrita na vida social humana, representa um requisito básico para o funcionamento efetivo das organizações e a satisfação de seus membros (REGO et al., 2002). Entretanto, ao aliar tais preocupações às questões ambientais e sociais, ou seja, a justiça socioambiental, poucos são os estudos localizados. Desta forma, para discutir o conceito de justiça socioambiental nas organizações, partiu-se de algumas discussões já pré-estabelecidas no âmbito da justiça ambiental, justiça social e justiça organizacional.

A noção de justiça ambiental remete a uma distribuição equânime de partes e à diferenciação qualitativa do meio ambiente (ASCERALD, 2002). Está atrelada à relação entre a exposição a riscos socioambientais e desigualdade socioeconômica, incluindo classes econômicas mais baixas e etnias 
marginalizadas (VEIGA, 2007; URKIDI; WALTER, 2011). Simplificadamente, a justiça ambiental se baseia no princípio de que todos têm o direito de proteção no ambiente da poluição, viver e desfrutar de um ambiente limpo e saudável. Justiça ambiental é a participação igual, proteção igual e significativa de todas as pessoas no que tange ao desenvolvimento, implementação e aplicação das leis, regulamentos e políticas ambientais, além da distribuição equitativa de benefícios do meio ambiente.

Apesar dos reconhecidos problemas que envolvem tanto a conceituação como prática da justiça ambiental, Agyeman e Evans (2004) acreditam na importância da justiça ambiental para a sustentabilidade. Para os autores, é necessário colocar o discurso da justiça ambiental firmemente no âmbito da sustentabilidade de modo a reconhecer as conexões entre justiça e equidade com questões mais amplas de governança. Legarda e Buendía (2011) complementam que o movimento de justiça ambiental reiterou publicamente o compromisso de promover a prevenção e redução da poluição industrial que incide sobre o planeta.

Não somente por meio de controles de poluição ambiental, mas a partir da revisão de princípios distributivos de impactos negativos e positivos, bem como da eliminação de crimes ambientais, acredita-se que as organizações podem contribuir de fato para gerar e manter a justiça ambiental no contexto onde ela atua, tendo em vista a sustentabilidade ambiental.

Aliada às discussões referentes à justiça ambiental está o fato de que ela amplia o debate tradicional, com questões que incluem a justiça social (LEGARDA; BUENDÍA, 2011). É muito improvável haver justiça ambiental se não há justiça social. Esta é considerada um termo de difícil definição, porém, frequentemente associada a direitos humanos e políticos (ROBERTS, 2003). A justiça social concerne tanto a aspectos econômicos quanto culturais da sociedade, logo, intimamente ligada ao interesse público (RIDELL, 2009), e ao reconhecimento da importância da diferença e da diversidade nas sociedades (CRAIG, 2009).

A justiça social associa-se normalmente aos grupos marginalizados da sociedade, no que tange à etnia, orientação sexual, classe socioeconômica, condição de saúde e educação, entre outros (RIDDEL, 2009). Há também as expressões e aplicações da justiça social referentes a causas e consequências de dimensão espacial, por exemplo, o acesso ao transporte público, oportunidades de emprego, acesso a tratamentos de saúde, etc. (ROBERTS, 2003). Em síntese, a justiça social envolve os seguintes valores: alcançar a equidade e igualdade de resultados e tratamento de toda a sociedade; reconhecer a dignidade e incentivar a autoestima de todos; reunir as necessidades básicas, definidas através do consenso transcultural; reduzir as desigualdades substanciais nas chances de geração de renda e vida; e buscar, na sociedade, a participação de todos, incluindo os mais desfavorecidos (CRAIG, 2009).

Para Roberts (2003), a redução da exclusão social e a promoção da coesão e da justiça social são objetivos fundamentais, com reflexos no progresso econômico e também na gestão do meio ambiente. Ao se pensar no caso das organizações, é esperado que as organizações encarem a justiça social como fim desejável em si, sem que retornos econômicos assumam qualquer prioridade. A partir das ações das organizações é possível alcançar maiores níveis de equidade social mediante oferta de oportunidades iguais, inclusão de minorias, práticas não discriminatórias e gestão da diversidade (TOMLINSON; SCHWABENLAND, 2010).

A justiça, de fato, tem sido um foco de estudo na teoria das organizações já por quase meio século, e, atualmente, apresenta um corpo teórico extensivo e robusto. De maneira simplificada, a justiça 
organizacional lida com o papel da justiça no local de trabalho. Whiteman (2009) ressalta que as questões sobre justiça permeiam todo tipo de interação social e não se restringem às relações empregador-empregado. As relações com stakeholders podem agregar ricas contribuições, em razão de que estas relações podem estar envoltas a conflitos de cultura e dinâmicas de poder, aspectos diretamente vinculados ao conceito.

Estudos sobre a justiça organizacional encontram-se basicamente em cinco perspectivas: a noção de justiça distributiva (percepção da justiça sobre os resultados); a justiça procedimental (percepção sobre os meios determinados para alcançar resultados); a justiça interacional (percepção sobre a qualidade da interação com os decisores), dividida em justiças interpessoal (percepção sobre o tratamento digno e respeitoso) e informacional (percepção sobre o fornecimento de informações e a justificativa das decisões) e a justiça política (percepção sobre as políticas organizacionais) (ROBBINS; SUMMERS; MILLER, 2000; REGO et al., 2002; WHITEMAN, 2009; BROWN; BEMMELS; BARCLAY, 2010).

Seja qual for a instância de justiça organizacional, e sua incidência sobre as dimensões social e ambiental, é consenso que as percepções de justiça ou injustiça acarretam efeitos expressivos nos processos e resultados organizacionais, como o desempenho da organização, cooperação, comportamento cidadão, abstinências, ociosidade, estresse, roubos, atrasos, sabotagens, entre outros (WHITEMAN, 2009).

A justiça representa um requisito básico para o funcionamento efetivo das organizações e o comportamento de seus membros, ao tratar-se de questões mais amplas da sustentabilidade, esta exigência torna-se inquestionável.

Atender às premissas da ecoeficiência e da justiça socioambiental mostra-se necessário ao alcance da S.A., além de potencializar o alcance da S.O.. O desafio agora é traduzir os conceitos em orientações para sua prática. Isso será aqui porposto por meio de um modelo de gestão que permita às organizações atuarem de forma inter-relacionada ao seu meio externo, ao mesmo tempo em que operem em sintonia com seus processos internos, visando ao alcance da S.A., como um caminho para o alcance da S.O..

\section{CONSTRUÇÃO E PROPOSIÇÃO DO FRAMEWORK EXPLICATIVO DA GESTÃO DA S.A. EM CONTEXTO EMPRESARIAL}

Para Munck, Munck e Borim-de-Souza (2011), o FRASOR requer o alinhamento entre estratégia, competências e objetivos organizacionais. Entende-se alinhamento como a coesão, o ajuste e a congruência entre diferentes dimensões, podendo atuar simultaneamente como processo e resultado. Assim é assumido como uma dinâmica de ajuste da organização com o ambiente ou como um mecanismo de mobilização dos recursos organizacionais em função da interatividade inerente aos processos estratégicos (GALBRAITH; KAZANJIAM, 1986). A congruência revela a convergência entre competências e demandas encontrada em quatro níveis: nível organizacional; nível dos processos essenciais da organização; nível dos subprocessos que compõem o processo essencial; e nível individual (BAKER et al., 1997).

Segundo Munck e Borim-de-Souza (2011), traduzir os agires organizacionais em competências organizacionais concede-lhes objetividade na descrição e condições de registrar eficiência na ação organizativa frente aos resultados almejados. Assim, a S.O., enquanto um agir organizacional, estará articulada ao agir social e vinculada à estratégia organizacional, bem como a uma série de recursos organizacionais. A competência, em seus três diferentes níveis, "relata eficiência, ou seja, o melhor uso 
possível e articulado dos recursos. É ela meio de fomento e verificação da eficácia nos processos de ações e decisões" (MUNCK, MUNCK, BORIM-DE-SOUZA, 2011, p.152). As competências constituem, dessa forma, o agir organizacional mobilizador de recursos e formador de uma cadeia de relacionamento capaz de retratar o caminho para o acontecimento da S.O., considerarando as influências externas. Por este entendimento, indica-se que há, nas teorizações propostas pelos autores supracitados, plausibilidade em auferir a congruência interna ao FRASOR.

Para Maggi (2006), o agir organizacional é um macroprocesso consequente de inúmeros subprocessos, influenciado tanto por processos externos quanto internos. Para o autor, o processo é permanente, jamais terminado, que ocorre em todos os níveis - desde a ação do sujeito singular às relações de ações de numerosos sujeitos. As organizações são vistas como forma de agir e, consequentemente, como um processo de ações e decisões. Assim, o agir organizacional concerne tanto aos processos de ação de um sujeito quanto aos processos de ação coletiva, ainda que todo processo organizacional guarde relação com outros processos. Observa-se a relação processual intrínseca e mútua entre as organizações e o ambiente externo, entre o agir organizacional e social, algo imprescindível na busca pelo desenvolvimento sustentável, S.O. e S.A..

O estabelecimento do desenvolvimento sustentável como um agir social, da S.O. como um agir organizacional e da S.A. como um subagir organizacional, como preconizado por Munck, Munck e Borim-deSouza (2011), tornam-se mais pertinentes e coesos, se observado por este contexto de relações processuais mútuas entre organização e ambiente externo, em que aquela se antecipa em se adequar para fornecer respostas a este, quando demandadas.

As competências também aparecem na relação entre organizações e ambiente externo, já que é conceito essencial no FRASOR, representando a operacionalização dos fundamentos da sustentabilidade. $\mathrm{O}$ desenvolvimento das competências organizacionais é tido como intimamente ligado às condições dadas pelo âmbito externo, tendo em vista que a organização existe em um contexto amparado por um ambiente que vai além de seus limites físicos, composto por comunidades políticas, práticas industriais e ciclos econômicos (BOYATZIS, 1982). Ou seja, a organização assume uma postura proativa ao mobilizar sua estrutura interna a fim de responder ou se antecipar às demandas externas.

A partir das reflexões postas, nota-se que alguns detalhamentos podem ser acrescidos ao FRASOR, bem como nos próprios conceitos designados pelo framework em questão. Com base nas fundamentações apresentadas nos tópicos anteriores, nos próprios trabalhos de Munck, Munck e Borim-de-Souza (2011) e Munck (2013), e na contribuição a respeito da coerência externa do FRASOR, tais definições foram revisitadas e aprimoradas de forma a tornarem-se mais robustas e traduzíveis em práticas organizacionais. A S.O., a S.A., a ecoeficiência e a justiça socioambiental ficaram assim definidas. Vide Quadro 2. 
Quadro 2 - Definições revisitadas dos conceitos constituintes do FRASOR.

\begin{tabular}{l}
\hline \multicolumn{1}{c|}{ Sustentabilidade Organizacional } \\
\hline $\begin{array}{l}\text { Competência organizacional central que representa e orienta o equilibrio sistêmico e balanceado de investimentos e resultados referentes à S.E., S.S. e S.A.. } \\
\text { Insere-se holisticamente na organização, considerando trade-offs e permitindo a construção de uma plataforma de aprendizagem a partir da interação com } \\
\text { toda a cadeia de stakeholders. Sua incorporação deve alinhar-se ao contexto ambiental e aos preceitos do desenvolvimento sustentável da sociedade. }\end{array}$ \\
\hline \multicolumn{1}{c|}{ Sustentabilidade Ambiental } \\
\hline $\begin{array}{l}\text { Competência organizacional chave que representa e orienta o equilíbrio sistêmico e balanceado de investimentos e resultados referentes à ecoeficiência e a } \\
\text { justiça socioambiental. É um subsistema da S.O. que descreve a realização eficaz de dois agires organizacionais menores, ou seja, das entregas definidas } \\
\text { para a justiça socioambiental e a ecoeficiência. Seus objetivos abrangem a prevenção e a minimização dos impactos negativos que possam afetar o acesso } \\
\text { das gerações futuras aos recursos naturais críticos. Bemcomo, a amplificação dos impactos positivos gerados pela organização nos sistemas naturais.. }\end{array}$ \\
\hline $\begin{array}{l}\text { Competência organizacional de suporte que representa e orienta o intercambiar de objetivos e resultados econômicos e ambientais de forma que haja } \\
\text { benefícios mútuos e ampliados para a S.A.. Suas entregas envolvem a oferta de produtos e serviços a preços competitivos de forma que satisfaçam as } \\
\text { necessidades humanas e promovama preservação ambiental. }\end{array}$ \\
\hline $\begin{array}{l}\text { Competência organizacional de suporte que representa e orienta o conduzir das atividades organizacionais à luzdas justiças social e ambiental, considerando } \\
\text { as suas dimensões distributiva, procedimental, interpessoal, informacional e política. Suas entregas referem-se ao subsidio de conhecimento, formação e } \\
\text { oportunidades para o corpo funcional e para os stakeholders da organização a fim de que se minimize as injustiças e desigualdades socioambientais que os } \\
\text { circundam. }\end{array}$ \\
\hline
\end{tabular}

Fonte: elaborado pelos autores a partir de Munck, Munck e Borim-de-Souza (2011) e Munck (2013)

Adotou-se como referência para a construção do ciclo de aprendizagem orientador da gestão da S.A., o raciocínio proposto nos trabalhos de Munck e Munck (2008) e Munck (2013). O raciocínio é razoavelmente simples: O ciclo, não necessariamente possui um início ou um fim. Em um primeiro momento, todavia, é necessária a definição da estratégia organizacional e de seus respectivos desdobramentos para os níveis táticos e operacionais. A execução da estratégia em pauta será viabilizada pelas competências organizacionais, que representam a operacionalização sistêmica dos recursos. Em decorrência, os recursos são influenciados e modificados pela resposta obtida pela estratégia, o que novamente provoca e até mesmo exige novas configurações dos recursos, que poderão ou não implicar modificações ou até na necessidade de uma nova estratégia. O ciclo posiciona a aprendizagem, embora se entenda que ela ocorra em todas as fases do processo, em seu final formal. Nesta fase, ela tende a ocorrer com parâmetros consistentes e coerentes a fim de melhor orientar a revisão dos recursos e sua articulação frente aos objetivos deflagrados pela estratégia.

Ao aplicar-se este raciocínio à estrutura do FRASOR, tem-se a S.O. enquanto uma competência central sob a responsabilidade do nível estratégico e a S.A. como uma competência chave sob a responsabilidade do nível tático. A ecoeficiência e a justiça socioambiental são identificadas como as competências organizacionais de suporte que permitem o alcance das referidas competências. Com base nas discussões prévias, a título de exemplificação, foram destacados três possíveis recursos que deverão ser mobilizados para cada uma destas duas competências acontecerem, como indica a Figura 2. 
Figura 2 - Representação do ciclo de aprendizagem para a formação da competência Sustentabilidade Ambiental.

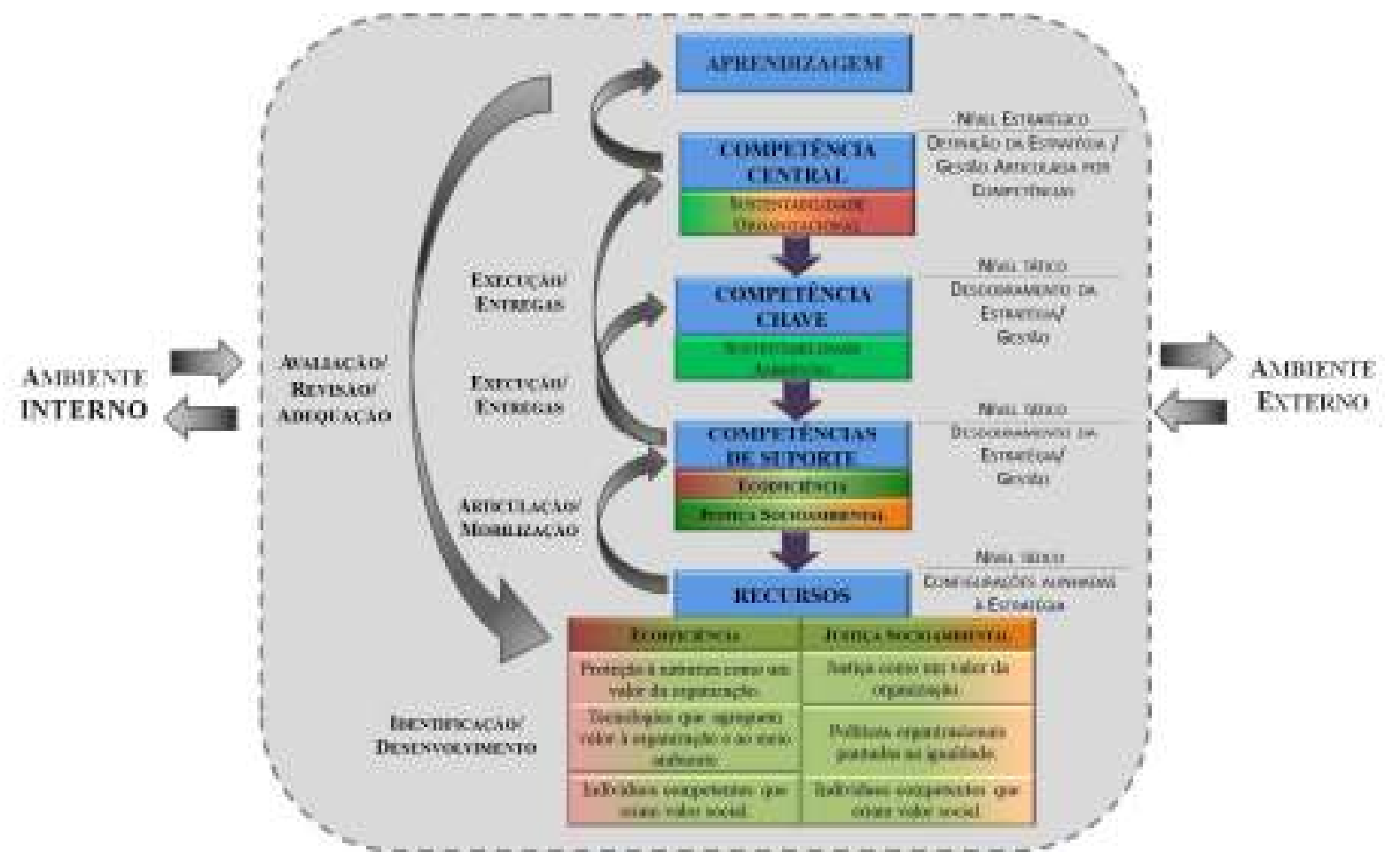

Fonte: elaborado pelos autores a partir das contribuições de Munck e Munck (2008); Munck e Borim-de-Souza (2011) e Munck (2013).

A estratégia organizacional e seus objetivos (vinculados à S.O.) proporcionam os direcionamentos para os agires organizacionais em níveis táticos (S.A.) e operacionais, para a gestão articulada por competências e para a configuração de recursos necessários, conforme indicam as setas em roxo e as indicações ao lado direito da figura. A partir daí, observando as setas e indicações à esquerda, a organização identifica seus recursos ou a falta ou excesso dos mesmos, alinhados às prerrogativas estratégicas e, em seguida, trabalha no seu desenvolvimento e/ou preenchimento de lacunas. Com os recursos identificados, estes são mobilizados e articulados, constituindo as competências de suporte, Ecoeficiência e Justiça Socioambiental. Estas competências são então colocadas em ação, buscando suas respectivas entregas, a fim de que se viabilize o atingimento das entregas determinadas pela Sustentabilidade Ambiental. Por sua vez, a S.A. é também executada e entregue de forma orientada ao alcance da Sustentabilidade Organizacional.

$\mathrm{Na}$ realização da estratégia, durante toda a passagem do ciclo, aprende-se conforme os erros, acertos, carências e sobras em termos de recursos e competências; consequentemente desencadeia-se um processo de mudança no sentido de adquiri-los, aprimorá-los ou corrigi-los. Análises são sugeridas a fim de averiguar atuais e buscar novos padrões de vinculação entre resultados e estratégias organizacionais. Os recursos para a ecoeficiência e justiça socioambiental são disponíveis e possíveis de serem compartilhados, contudo, sua simples existência não se traduz necessariamente no alcance da S.A.. São as entregas esperadas para as competências organizacionais ecoeficiência e justiça socioambiental que, inicialmente, ditarão os parâmetros para se dizer quão bem, ou não, a organização tem o desempenho adequado para a viabilização da S.A. e, por conseguinte, da S.O.. Do mesmo modo, as entregas da S.A., por si, associam-se à viabilização da S.O.. Esta visão sistêmica é inerente ao ciclo de aprendizagem em proposição. 
O mesmo pode ocorrer em relação às estratégias que podem ser readequadas, conforme verificação de desvios e alterações diversas no ambiente organizacional. A mobilização dos recursos, a adequação de estratégias e sua execução aparecem interligadas não só ao ambiente interno, mas também ao externo indicando a relação processual e entre estes elementos. Conforme o entendimento sobre S.A, ecoeficiência e justiça socioambiental, os relacionamentos da organização são fundamentais para a gestão destes elementos. Mudanças importantes na legislação ambiental, nas normas e padrões do comércio nacional e internacional (por exemplo, em relação à certificações), ou até mesmo novas exigências de fornecedores e consumidores a respeito de padrões de qualidade e atuação justa, assim como decisões de mudanças na própria organização (por exemplo, alterações nos planos de carreira ou novas plantas industriais), afetam diretamente a responsabilidade sobre a S.A. (e S.O. também), desencadeando a necessidade de revisões sobre estratégia, entregas de competências e recursos.

Embora, o foco deste artigo tenha sido direcionado à sustentabilidade ambiental, é preciso lembrar que esta compõe um sistema em que a alteração em um dos subsistemas afeta os outros. Dessa monta, considerações direcionadas à S.A., afetam diretamente às premissas definidas para a S.O. e vice-versa válido também para os demais componentes do FRASOR.

\section{CONSIDERAÇÕES FINAIS}

Este artigo visou à delinear um framework capaz de representar e orientar o acontecimento da Sustentabilidade Ambiental nas organizações atuando, assim, como referência para a sua operacionalização e gestão. Delineou-se um processo retroalimentativo do alinhamento dos agires da Sustentabilidade Organizacional, o qual culminou em um ciclo de aprendizagem que permeia a construção de competências voltadas à S.A. e, consequentemente, à S.O.. Neste ciclo, a identificação e a mobilização dos recursos, a adequação de estratégias organizacionais e sua execução aparecem interligadas ao ambiente interno e externo, indicando a relação processual entre estes elementos.

Intentou-se com este trabalho disponibilizar às organizações, aos seus gestores e a outros atores sociais envolvidos, uma arquitetura de gestão, ainda que inicial, capaz de orientar o desenvolvimento de ações estratégicas voltadas à S.A., de maneira coerente e aprimorada em relação as já existentes. Avançar na prática da sustentabilidade é imperante, e a capacidade da academia em incitar debates e propiciar uma abordagem de gestão holística é fundamental.

O ciclo apresentado destaca a ecoeficiência e a justiça socioambiental enquanto competências organizacionais de suporte à S.A., permitindo que a gestão relativa aos aspectos ambientais (em maior escala), econômicos, e sociais da empresa seja parte de uma gestão sistêmica, abrangente e integradora direcionada para o desenvolvimento sustentável da organização. Formalizar a sustentabilidade em práticas já reconhecidas no cenário organizacional, como a gestão por competências - sobretudo por seus benefícios -, significa disponibilizar meios para que este fenômeno possa ser melhor compreendido, praticado e vivenciado nas organizações.

É possível notar que a execução da S.A. a partir do ciclo em proposição está diretamente associada ao nível estratégico da organização. Isso significa que gestores nesta posição devem assumir esta responsabilidade, desenvolver e disseminar o alinhamento entre estratégia e resultados de sustentabilidade 
por toda organização. As decisões que orientam as atividades da organização em relação à sustentabilidade ocorrem basicamente, portanto, em nível estratégico e são refletidas para os níveis tático (em que também podem acontecer decisões mais pontuais) e operacional. Implicações devem ocorrer no que tange à formação destes gestores, por exemplo, em relação à liderança, comunicação e conhecimento de fato a respeito da sustentabilidade ambiental, ecoeficiência e justiça socioambiental.

As propostas de utilização de um framework de gestão da S.A. como feito inicialmente pelo FRASOR e neste artigo, no sentido do detalhamento de sua operacionalização, mostram-se como perspectivas possíveis para a gestão da sustentabilidade, de forma objetiva e ao mesmo tempo abrangente. As competências mostraram-se como alternativa viável à gestão da sustentabilidade organizacional, pois ao assumirem a função de traduzir a relação entre os processos do ambiente externo e da organização junto aos seus membros, permitem delimitar e orientar ações objetivas e coerentes com a S.O., S.A. e seus demais componentes.

Além disso, a sustentabilidade gerida nos termos da lógica das competências estimula valores relacionados a um desenvolvimento sustentável ancorado em parâmetros objetivos e alinhados à estratégia em pauta. Contribui ainda para a visão de cooperação, a partir da qual as premissas envoltas à sustentabilidade são passíveis de serem melhores e mais facilmente atendidas.

Acredita-se que as conexões entre os estudos e a prática da gestão aqui apresentadas possam ampliar a visão e a compreensão da S.A. em contexto organizacional, haja vista articula as perspectivas micro e macro de seu acontecimento. Este trabalho pretende servir de reflexão para a academia, para as empresas e para a sociedade ao agregar conhecimentos valiosos de apoio à gestão e, a partir dai, propor contribuições que almejem gerar novas respostas, críticas e novas visões.

Pesquisas futuras são sugeridas no sentido de ampliar o entendimento contido no framework proposto para os outros componentes do FRASOR, além de detalhá-lo em ações específicas, em estudos empíricos. Sabe-se que é uma tendência da gestão por competências que primeiro sejam definidas bases conceituais, para que depois entregas sejam apontadas e, na sequência, indicadores e planos de ação sejam desenvolvidos. Como pauta para futuras pesquisas, portanto, sugere-se a validação do framework em contexto organizacional, bucando seu refinamento e aproximação com a realidade empresarial. Outro estudo envolveria a tradução e transposição das ações organizacionais para as ações dos indivíduos, medidas por entregas e indicadores da sustentabilidade organizacional. 


\section{REFERÊNCIAS}

ACSELRAD, H. Justiça ambiental e construção social do risco. In: XIII Encontro da Associação Brasileira de Estudos Populacionais, 2002, Ouro Preto, Minas Gerais. Anais... XIII Encontro ABEP, 2002.

AGYEMAN, J.; EVANS, B. 'Just sustainability': the emerging discourse of environmental justice in Britain?.The Geographical Journal, v.170, n.2, p.155-164, 2004.

ASADI, A.; AKBARI, M.; FAMI, H.S.; IRAVANI, H.; ROSTAMI, F.; SADATI, A. Poverty alleviation and sustainable development: the role of social capital. Journal of Social Sciences, v.4, n.3, p.202-215, 2008.

AZAPAGIC, A. Systems approach to corporate sustainability: a general management framework. Trans IChemE, v. 81, 2003.

BAKER, J.C.; MAPES, J.; NEW, C.C.; SZWEJCZEWSKI, M.. A hierarchical model of business competence. Integrated Manufacturing Systems, v. 8, n. 5, p. $26-272,1997$.

BARKEMEYER, R.; HOLT, D.; PREUSS, L.; TSANG, S. What Happened to the 'Development' in Sustainable Development? Business Guidelines Two Decades After Brundtland. Sustainable Developlment, 2011.

BORIM-DE-SOUZA, R. O alinhamento entre sustentabilidade e competências em contexto organizacional. Dissertação (Mestrado em Administração). Universidade Estadual de Maringá (UEM) / Universidade Estadual de Londrina (UEL), Londrina, 2010.

BOYATZIS, R. E. The competent management: a model for effective performance. New York: John Wiley, 1982.

BRAUNGART, M.; MCDONOUGH, W., BOLLINGER, A. Cradle-to-cradle design: creating healthy emissions e a strategy for eco-effective product and system design. Journal of Cleaner Production, 2006.

BROWN, G.; BEMMELS, B.; BARCLAY, L.J.. The importance of policy in perceptions of organizational justice. Human Relations, v. 63, n.10, p. 1587-1609, 2010.

CHENG, C. Y;. FET, A. M.; HOLMEN, E. Using a Hexagonal Balanced Scorecard approach to integrate Corporate Sustainability into Strategy, Proceedings for the 16th International Sustainable Development Research Conference, Hong Kong, 2010.

CRAIG, G. Civil society associations and the values of social justice. London: Carnegie UK Trust, 2009.

DREJER, A. Strategic management and core competencies. Quorumbooks, USA, 2002.

DYLLICK, T.; HOCKERTS, K. Beyound the business case for corporate sustentability. Business Strategy and the Environment. v.11, p.130-141, 2002.

ELKINGTON, J. Cannibals with forks: the triple bottom line of 21st century business. Oxford: Capstone Publishing Limited, 1999.

FERNANDES, B.H.R.; FLEURY, M.T.L.; MILLS, J. Construindo o diálogo entre competência, recursos e desempenho organizacional. Revista de Administração de Empresas - RAE. São Paulo, v. 46, n. 4, p.48-65, 2006

FLEURY, A.; FLEURY, M. T. L. (2008). Estratégias empresariais e formação de competências: um quebra-cabeça caleidoscópico da indústria brasileira. 3 ed. São Paulo: Atlas.

FLEURY, M. T. L; FLEURY, A. C. C. Alinhando estratégia e competências. Revista de Administração de Empresas, v.44, n.1, p.44-57, 2004.

FLICK, U. Introdução à pesquisa qualitativa. 3. ed. Porto Alegre: Artmed, 2009.

FORTIN, M.; FELLENZ, M. R. Hypocrisies of Fairness: towards a more reflexive ethical base in organizational justice research and practice. Journal of Business Ethics, v.78, p.415-433, 2008.

GALBRAITH, J.R.; KAZANJIAN, R.K. Strategy implementation: structure, systems and process. St. Paul: West Publisher, 1986.

GALLELI, B.; MUNCK, L.; PILLI, L. E.; MAZZON, J. A. A Model for Organizational Sustainability Management: a Structural Equation Modeling approach. Business Systems Review, v. 3, n. 2, p. 142-163, 2014.

GUENSTER, N.; BAUER, R.; DERWALL, J.; KOEDIJK, K. The Economic Value of Corporate Eco-Efficiency. European Financial Management, v. 17, n. 4, p. 679-704, 2011.

HACKING, T.; GUTHRIE, P. A framework for clarifying the meaning of the triple bottom-line, integrated, and sustainability assessment. Environmental Impact Assessment Review, v. 28, n. 2-3, p. 73-89, 2008.

HAHN, T.; SCHEEMESSER, M. Approaches to Corporate Sustainability among German Companies. Corporate Social Responsability and Environmental Management, 2005.

HUKKINEN, J. Eco-efficiency as Abandonment of Nature. Ecological Economics, v. 38,

n. 3, p. 311-315, 2001 
JABAREEN, Y. Building a conceptual framework: philosophy, definitions, and procedure. International Journal of Qualitative Methods, v.8, n.4, p.49-62, 2009.

LEGARDA, A. A.; BUENDÍA, M. P. Justicia ambiental: El estado de la cuestión. Revista Internacional de Sociología, v.69, n.3, 2011.

LEWIS, M.A.. Analysing organisational competence: implications for the management of operations, International Journal of Operations \& Production Management, v. 23, n. 7, p.731-756, 2003.

MAGGI, B. Do agir organizacional. São Paulo: Edgard Blücher, 2006.

MARKUS, L.H., COOPER-THOMAS, H.D., ALLPRESS, K.N. Confunded by competencies? An evaluation of the evolution and use of competency models. New Zealand Journal of Pshycology, v.34, n.2, p. 117-126, 2005.

MILLS, J.; PLATTS, K.; BOURNE, M.; RICHARDS, H. Competing though competences. Cambridge: Cambrigdge University Press, 2002.

MILNE, M.J.; KEARINS, K.; WALTON, S. Creating adventures in wonderland: the journey metaphor and environmental sustainability. Organization, v. 13, v. 6, 801-839, 2006.

MOLDAN, B.; JANOUSKOVA, S.; HAK, T. How to understand and measure environmental sustainability: Indicators and targets. Ecological Indicators, v. 17, p. 4-13, 2012.

MOLTENI, M.; PEDRINI, M. In search of socio-economic syntheses. Journal of Management Development, v. 29, n. 7/8, p. 626-636, 2010.

MORELLI, J. Environmental Sustainability: A Definition for Environmental Professionals. Journal of Environmental Sustainability, v. 1, n. 1, p. 1-9, 2011.

MUNCK, L. Gestão da Sustentabilidade nas Organizações: reflexões e propostas a partir das lógicas do agir organizacional e das competências. São Paulo: Cengage Learning, 2013.

MUNCK, L.; BANSI, A. C.; GALLELI, B.; CELLA-de-OLIVEIRA, F. A.. Em busca da sustentabilidade organizacional: a proposição de um framework. Revista Alcance (Online), v. 20, n. 4, p. 460-4772, 2013.

MUNCK, L; GALLELI, B. Mutualismo Eco-Ambiental como alternativa à ecoeficiência em modelos sistêmicos voltados à gestão da sustentabilidade. In: Colóquio Internacional sobre Poder Local, 12. Anais... XII Colóquio sobre Poder Local. Salvador, 2012.

MUNCK, L.; MUNCK; M.G.M (2008). Gestão organizacional sob a lógica da competência: aplicação na pequena empresa. Revista de Administração Mackenzie - RAM, v. 9, n. 1, 64-85.

MUNCK, L.; MUNCK, M.G.M.; BORIM-DE-SOUZA, R. Sustentabilidade organizacional: a proposição de uma framework representativa do agir competente para seu acontecimento. Gerais: Revista Interinstitucional De Psicologia, v. 4, n. 2, ed. Especial, p. 147-158, 2011.

PIOTTO, Z.C. Eco-eficiência na Indústria de Celulose e Papel: estudo de caso. Tese (Doutorado em Engenharia) Escola Politécnica - Engenha Sanitária e Hidráulica - USP. Universidade de São Paulo, 2003

POLIZELLI, D.L.; PETRONI, L.M.; KRUGLIANSKAS, I. Gestão ambiental nas empresas líderes do setor de telecomunicações no Brasil. Revista de Administração, v.40, n.4, p.309-320, 2005.

RAWLS, J. Uma Teoria da Justiça. São Paulo: Martins Fontes, 1997.

REGO, A., CARVALHO, M. T., LEITE, R., FREIRE, C., VIEIRA, A.. Justiça nas organizações: um modelo tetradimensional. Revista de Psicologia Organizacional e do Trabalho, v. 2, n. 2, p. 113-142, 2002.

ROBBINS, T.L.; SUMMERS, T.P.; MILLER, J.L.. Intra- and inter-justice relationships: Assessing the direction. Human Relations, v. 53, n.10, p.1329-1355, 2000.

ROBERTS, P. Sustainable development and social justice: spatial priorities and mechanisms for delivery. Sociological Inquiry, v. 73, n. 2, p. 228-244, 2003.

RIDDELL, S. Social justice, equality and inclusion in Scottish education. Discourse: Studies in the Cultural Politics of Education, v. 30, n. 3, p. 283-296, 2009.

SCHAFFEL, S.B. Em busca da Eco-Sócio Eficiência no caso da agricultura familiar voltada para a produção de biodiesel no Brasil. Tese. (Doutorado em Planejamento Energético). Universidade Federal do Rio de Janeiro, Rio de Janeiro, 2005.

SPANOS, Y.E.; PRASTACOS, G. Prastacos, Understanding organizational capabilities: towards a conceptual framework. Journal of Knowledge Management, v. 8, n.3, p. 31-43, 2004.

STUBBS, W.; COCKLIN, C.. Conceptualizing a 'Sustainability Business Model'. Organization \& Environment, v. 21, n.2, p. 103-127, 2008.

TOMLINSON, F.; SCHWABENLAND, C. Reconciling Competing Discourses of Diversity? The UK Non-Profi t Sector Between Social Justice and the Business Case. Organization, v. 17, n. 1, p. 101-121, 2010. 
URKIDI, L.; WALTER, M. Dimensions of environmental justice in anti-gold mining movements in Latin America. Revista Geoforum - Elsevier, v.42, p.683- 695, 2011.

VAKOLA, M.; SODERQUIST, K.E.; PRASTACOS, G.P.. Competency management in support of organisational change. International Journal of Manpower, v. 28, n. 3, p. 260- 275, 2007.

Van MARREWIJK, M.; WERRE, M. Multiple Levels of Corporate Sustainability. Journal of Business Ethics, v. 44, n. 2-3, p. 107-119, 2003

VEIGA, M. M. Agrotóxicos: eficiência econômica e injustiça socioambiental. Ciência \& Saúde Coletiva, v. 12, n. 1, p.145$152,2007$.

WERNERFELT, B.. A Resource-based View of the Firm. Strategic Management Journal, 5, 171-180, 1984.

WHEELER, D.; ELKINGTON, J.. The end of the corporate environmental report? Or the advent of cybernetic sustainability reporting and communication. Business Strategy and the Environment, v. 10, n.1, 2001.

WHITEMAN, G. All My Relations: Understanding Perceptions of Justice and Conflict between Companies and Indigenous Peoples. Organization Studies, v.30, n.1, p. 101-120, 2009.

WORLD BUSINESS COUNCIL FOR SUSTAINABLE DEVELOPMENT - WBCSD. A eco-eficiência: criar mais valor com menos impacto. Lisboa, 2000.

YOUNG,W. TILLEY, F.. Can Businesses Move Beyond Efficiency? The Shift toward Effectiveness and Equity in the Corporate Sustainability Debate Business. Business Strategy and the Environment, v.15, pg. 402-415, 2006.

ZARIFIAN, P. O modelo da competência. São Paulo: SENAC Editora, 2003. 